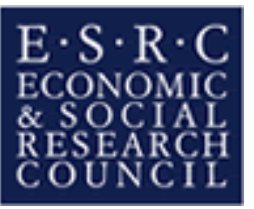

\title{
Measuring Potential Gains from Mergers among Electricity Distribution Companies in Turkey using a Non-Parametric Model
}

\author{
by
}

\author{
Necmiddin Bagdadioglu \\ Department of Public Finance, Hacettepe University, Turkey and \\ ESRC Centre for Competition Policy, University of East Anglia, UK \\ Catherine Waddams Price* \\ ESRC Centre for Competition Policy, and Norwich Business School, \\ University of East Anglia, UK \\ Thomas Weyman-Jones \\ Department of Economics, Loughborough University, UK
}

\section{CCP Working Paper 06-13}

\begin{abstract}
Turkish electricity reform is entering a new phase through the Turkish Government's proposal to create 21 new distribution companies, 18 of them through merger. Two aspects of merger analysis are the operational cost savings and the potential production efficiency gains. This paper concentrates on the second aspect and uses a recently developed methodology to assess the potential effect of these mergers and whether these mergers are efficiency enhancing. This is performed by comparing the actual efficiency levels of observed distribution companies with the merger of proposed aggregated companies. The model is calibrated on panel data from 1999 to 2003 which include measures of physical capital and labour inputs, as well as customer and energy related outputs. The results indicate potential for considerable efficiency gains from the proposed mergers.
\end{abstract}

September 2006

JEL Classification: G34; C14; L5; L94

Keywords: Efficiency and Productivity Analysis; Data Envelopment Analysis, Electricity Distribution 


\section{Acknowledgements:}

This paper has been produced with the financial assistance of the European Union, while Necmiddin Bagdadioglu was a visiting researcher, under the 2005/06 Jean Monnet Scholarship programme, at the ESRC Centre for Competition Policy of the University of East Anglia. The funding of the UK Economic and Social Research Council is gratefully acknowledged. Catherine Waddams thanks the University of California Energy Institute for hospitality. The content of this document is the sole responsibility of the authors and can not be regarded as reflecting the views of the funders. We are grateful to Morten Hviid, five anonymous referees of this Journal, and participants in the 2006 UK Efficiency and Productivity Analysis Network Conference in Leicester, and in staff seminars in Aston Business School and Norwich Business School for their helpful comments on earlier versions of this paper.

Contact details:

*Corresponding Author: Catherine Waddams, ESRC Centre for Competition Policy, University of East Anglia, Norwich NR4 7TJ; t: 01603 593715; f: 01603 591622; e:

\section{c.waddams@uea.ac.uk}




\section{INTRODUCTION}

Over the last two decades, many countries with different economic, social and political endowments, and a variety of institutional and legal capabilities and capacities have introduced reform measures to disaggregate and liberate their electricity markets (Al-Sunaidy and Green, 2006; Jamasb, Mota, Newbery and Pollitt, 2004). Amongst the reforming countries, Turkey is of special interest for two reasons. Firstly, although Turkey started the reform as early as 1984, the pace of the reform process has been very slow. Secondly, while most countries have been trying to introduce private ownership into their electricity sector, recently Turkey has moved in the opposite direction by nationalising three of her four private distribution operators. Aktas was nationalised in 2002, while Cukurova and Kepez, previously controlled by the same private company, were nationalised in 2003 . Kayseri is now the only private distribution company in Turkey ${ }^{1}$.

These nationalisations were justified by the need to end these companies' improper market activities ${ }^{2}$ (OECD, 2003), and prepare the industry for a final restructuring before privatisation. The 2004 Electricity Sector Reform and Privatisation Strategy Paper (ESRPSP) outlines the Government's proposals to privatise the electricity market, including the creation of 21 distribution companies. 18 of these are to be created through merger of 79 separate distribution organisations owned by the public utility, the Turkish Electricity Distribution Company (TEDAS). The sector currently consists of 82 separate distribution organisations ( 81 public and 1 private), operating on a provincial basis.

In this paper we apply a recently developed methodology by Bogetoft and Wang (2005) to investigate whether these proposed mergers in the Turkish electricity distribution sector promise potential efficiency enhancement. Bogetoft and Wang's

\footnotetext{
${ }^{1}$ The provinces served by the previously privately operated electricity distributors are IstanbulAnatolian part (Aktas), Mersin, Adana, and Hatay (Cukurova) and Antalya (Kepez). Kayseri Electricity Company serves the Kayseri province.

${ }^{2}$ In a previous study by Bagdadioglu, Waddams Price and Weyman-Jones (1996) these companies were identified as good examples of management relative to their publicly owned counterparts, and their nationalisation therefore raises questions about the real reasons for their apparently good earlier performance.
} 
(2005) model is for non-parametric measurement of the potential gains from mergers, and we use it to compare two different comparative static equilibria: the existing organisational structure of electricity services and the planned merged structure, in which the technical efficiency with which observed inputs are transformed to outputs is evaluated relative to the existing structure. Related ideas have been discussed by Arocena (2005).

We describe a merger as advantageous if the merged producers could operate with greater technical efficiency than do the existing producers. The model identifies the scope for technical efficiency improvement through mergers, but to realize this potential some associated incentive mechanism is required. Our analysis does not provide a complete cost-benefit analysis of the proposed mergers, since we do not calculate the transaction or adjustment costs of the mergers, nor do we compute the discounted present value of the net efficiency gains. Because our concentration is on technical efficiency, neither do we address the allocative question of the possible creation of market power through the mergers. In any case, since each distribution company holds a local monopoly, such issues of market power are mainly relevant for providing comparative data to the regulator. In these senses our approach is different from the related studies in the empirical literature focusing on the organisational dimensions of electricity distribution using parametric measurement, as reviewed by Kwoka (2005).

The paper is organised in five main sections. Section 2 describes the Turkish electricity reform programme, focusing on the distribution sector in which we evaluate the progress so far. Section 3 outlines the model and our interpretation of the non-parametric measurements. We review two aspects of the analytical basis: the first is the description of the production set that characterises the technology that we wish to discuss; the second is the measurement of potential efficiency gains from mergers. Section 4 presents the data and the results. Section 5 discusses the results and explores the likely incentive mechanism under private ownership and regulation, which could create an environment to realise the potential gains which we identify. 


\section{TURKISH ELECTRICITY SECTOR REFORM}

Since 1980 Turkey's quest for a working market economy with a smaller public sector has been interrupted by intermittent economic crises, slowing the transformation process, and leaving the country to struggle with unfavourable economic conditions, high inflation, chronic budget deficits, and foreign and domestic debt problems ${ }^{3}$. These disrupted Turkey's ability to meet public investments in general, and in particular in the publicly-owned electricity sector. In 1984 Turkey initiated an ambitious electricity reform programme to add to, renew and maintain the generation and network facilities by using private capital and so reducing the strain on the public budget. The reform process has been supported and encouraged by World Bank and recently by the European Union (EU).

Turkey has made some progress in fulfilling the prerequisites for a so-called successful sector transformation, described by Jamasb, Newbery and Pollitt (2004) 4 . Monitoring the progress so far with these prerequisites, Turkey has legally unbundled the dominant public utility, the Turkish Electricity Authority (TEA); corporatised all newly-created public entities; and established the necessary legal and institutional framework. However, she has not yet privatised or introduced competition in the market for generation or supply; neither is there any competition for the market for transmission and distribution networks (European Commission, 2005).

The unbundling was gradual, and gained momentum after Turkey was recognised as an official candidate of EU in 1999. In 1993, TEA was split into two public

\footnotetext{
${ }^{3}$ The most recent crisis in May-June 2006 was relatively mild (the New Turkish Lira devalued by around 30\%) compared to the November 2000-February 2001 financial crisis when the Turkish currency was devalued by $50 \%$, nominal interest rates were around $100 \%$, and financial markets were severely affected. The dynamics and background to the November 2000-February 2001 crisis are discussed by Akyurek (2006), and Ozkan (2005).

${ }^{4}$ These prerequisites are as follows: (1) corporatisation of state-owned utilities, (2) enactment of electricity reform law, (3) regulatory reform, including adaptation of incentive regulation for natural monopoly network activities, (4) establishment of an independent regulator, (5) unbundling of vertically-integrated utilities into generation, transmission, distribution and supply activities, and where necessary horizontal splitting, (6) provision of third party access to networks, (7) establishment of a competitive wholesale generation market, (8) liberalisation of the retail supply market, (9) privatisation of electricity assets, and (10) definition of rules governing consumer protection, allocation of energy subsidies, and stranded costs.
} 
companies: the Turkish Electricity Generation and Transmission Company (TEAS) and TEDAS. In 2001, Turkey accelerated the process by enacting the Electricity Market Law (No: 4628) which is largely in line with the related European Commission Directive 2003/54/EC and Regulation 1228/2003. The EML established the independent sector regulator, the Energy Market Regulatory Authority (EMRA), and created three new public companies out of TEAS. Figure 1 presents the current structure of the electricity market, where the arrows show the directions of relationship between these players in the market.

Figure 1: Structure of Turkish electricity market

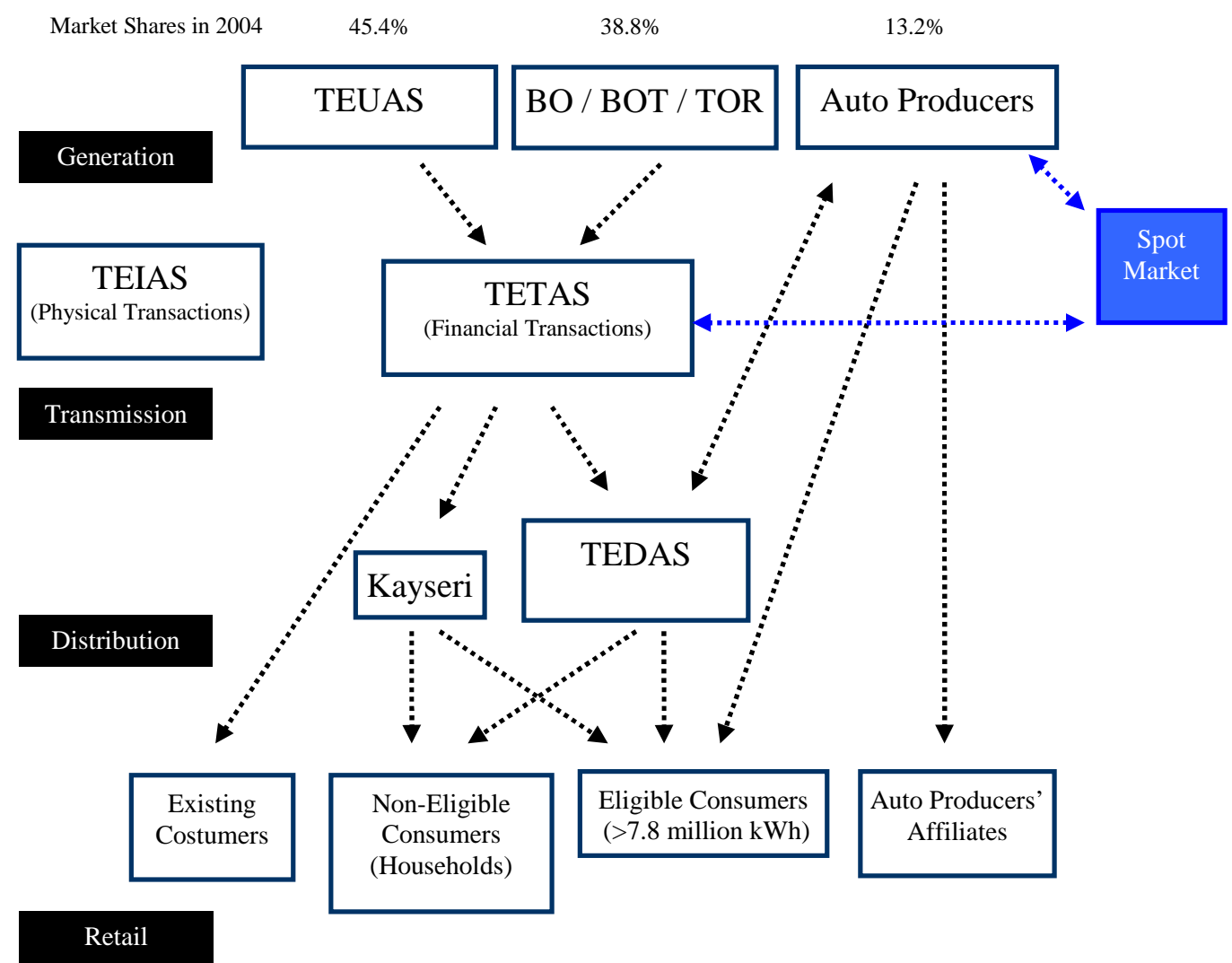

In March 2004, Turkey published the ESRPSP in compliance with the Energy acquis of EU, reflecting Turkey's ambitions to join the Union. The ESRPSP clarifies the sequences, and sets the deadlines for the electricity privatisation process to be accomplished in eight years from 2004. During this transitory period, the market for 
electricity ${ }^{5}$ is expected to rely on bilateral contracting between sellers and buyers, supported by a balancing and settlement regime. Licensing is the chosen way for new entry into the market. Private companies who want to participate in the Turkish electricity market are required to hold a relevant licence issued by EMRA ${ }^{6}$.

A comprehensive plan for the industry and its reform can be found elsewhere, for instance in Erdogdu (2006), Ozkivrak (2005), and Hepbasli (2005). In this section we focus on the distribution part of the Turkish reform programmes. The ESRPSP anticipates that the distribution facilities will be privatised first, following a major restructuring of TEDAS. This is not the first attempt to privatise distribution facilities, and the choice of commencing the privatisation process with TEDAS in the Turkish electricity sector is not arbitrary. Turkey's priority has always been to increase generation capacity to meet the growing demand. This caused disproportionate investment in generation plants to the detriment of distribution networks. Consequently consecutive governments could not meet urgently needed distribution network renewal and maintenance investments from the central budget. The obvious alternative was to seek private investment resulting in the first serious attempt to privatise TEDAS in 1993, when it was separated from TEA.

However, private investors insisted on international arbitration for dispute resolution which the legal framework could not accommodate at that time, delaying privatisation until Parliament amended the Constitution to permit such arbitration in 1999. During this time the Government continued to underinvest in the distribution network, so that the network losses (both technical and non-technical) reached alarming levels throughout the country, on average over 25\% during 1999-2003, as shown in table 2.

\footnotetext{
${ }^{5}$ In 2004, the total electricity generation and consumption was reported to reach 149.8 Twh and 149.2 Twh respectively. The major energy sources used for electricity generation were thermal (69.2\%), hydroelectric $(30.7 \%)$, and wind $(0.1 \%) .1 .1$ Twh of electricity was exported to Iraq, while $463 \mathrm{Gwh}$ of electricity was imported from Turkmenistan. The electricity load fluctuated during the year between 23,485 MW (maximum demand) and 12,485 MW (minimum demand). 47.4\% of generation is from local resources (EMRA, 2004).

${ }^{6}$ In terms of promoting competition, this transitory period is already handicapped by the presence of private companies operating under the schemes of Build-Operate (BO), Build-Operate-Transfer (BOT), and Transfer of Operating Rights (TOR) with a take-or-pay clause, which is likely to restrict competition emerging in the generation sector in the near future. Auto-producers, which may generate electricity for their own need, are also exploiting opportunities provided by the transitory period. They have recently been detected behaving strategically under the balancing and settlement regime, by decreasing their production to buy cheaper electricity at the low tariff period, while meeting their demand from their own plants during the high tariff period (EMRA, 2006).
} 
The privatisation of TEDAS is part of a comprehensive package including the whole electricity sector, and requires the prior completion of a number of preliminary steps related to tariff structure, market implementation, restructuring and licensing, and transition period contracts. Besides EMRA and TEDAS, there are several other governmental departments and organisations involved in various stages of this privatisation process. These are the Privatisation Administration (PA), the Ministry of Energy and Natural Resources (MENR), the Treasury, the State Planning Organisation (SPO), and the Turkish Electricity Transmission Company (TEIAS). On the distribution side MENR, TEDAS and EMRA have been working closely together to clarify the performance standards, loss targets and revenue requirements for the distribution companies. The tariff equalisation scheme is designed by MENR, EMRA and the Treasury. The involvement of so many governmental departments is creating a coordination problem, slowing the process and causing delays in the preparation for privatising the distribution organisations (European Commission, 2005).

As part of this process, in 2004, the ownership of TEDAS was transferred to the PA, and included in the privatisation programme. The PA has been working with its transaction advisors for distribution privatisation to prepare tender documents and on other related issues. Following this, privatisation of TEDAS is planned to be finalised by the end of 2006 .

The recent application of the PA for approval of the licences and tariff structures of 20 distribution companies is an important step forward. The licences and tariffs of the distribution companies were approved by EMRA in July 2006. Subject to any objections which may have been received, this completes the necessary legal framework for commencing privatisation of these distribution companies.

The creation of 21 new distribution companies is the focal point of this paper. 18 companies are formed through merger of 79 of the separate electricity distribution organisations of TEDAS. Table 1 and map 1 show the provinces included in these proposed merger areas and their geographical location respectively. Each company is constructed by merging several public electricity distribution organisations operating within a predefined service area. Istanbul, the largest city in Turkey, is currently 
served by two separate companies, each with a defined area. Kayseri is the only province presently served by a private company.

Table 1: Proposed Mergers

\begin{tabular}{|c|c|}
\hline Merger Area & The provinces included in the distribution region \\
\hline MA-1 & $\begin{array}{l}\text { D1(=DIYARBAKIR), D2(=MARDIN), D3(=SIIRT), } \\
\text { D4(=S.URFA), D5(=BATMAN), D6(=SIRNAK) }\end{array}$ \\
\hline MA-2 & D7(=BITLIS), D8(=HAKKARI), D9(=MUS), D10(=VAN) \\
\hline MA-3 & $\begin{array}{l}\text { D11(=AGRI), D12(=ERZINCAN), D13(=ERZURUM), } \\
\text { D14(=KARS), D15(=BAYBURT), D16(=ARDAHAN), } \\
\text { D17(=IGDIR) }\end{array}$ \\
\hline MA-4 & $\begin{array}{l}\text { D18(=ARTVIN), D19(=GIRESUN), D20(=GUMUSHANE), } \\
\text { D21(=RIZE), D22(=TRABZON) }\end{array}$ \\
\hline MA-5 & $\begin{array}{l}\text { D23(=BINGOL), D24(=ELAZIG), D25(=MALATYA), } \\
\text { D26(=TUNCELI) }\end{array}$ \\
\hline MA-6 & D27(=SIVAS), D28(=TOKAT), D29(=YOZGAT) \\
\hline MA-7 & $\begin{array}{l}\text { D30(=ADANA), D31(=MERSIN), D32(=OSMANIYE), } \\
\text { D33(=HATAY), D34(=G. ANTEP), D35(=KILIS) }\end{array}$ \\
\hline MA-8 & $\begin{array}{l}\text { D36(=KIRSEHIR), D37(=NEVSEHIR), D38(=NIGDE), } \\
\text { D39(=AKSARAY), D40(=KONYA), D41(=KARAMAN) }\end{array}$ \\
\hline MA-9 & $\begin{array}{l}\text { D42(=ANKARA), D43(=KIRIKKALE), D44(=ZONGULDAK), } \\
\text { D45(=BARTIN), D46(=KARABUK), D47(=CANKIRI), } \\
\text { D48(=KASTAMONU) }\end{array}$ \\
\hline MA-10 & D49(=ANTALYA), D50(=BURDUR), D51(=ISPARTA) \\
\hline MA-11 & D52(=IZMIR), D53(=MANISA) \\
\hline MA-12 & $\begin{array}{l}\text { D54(=BALIKESIR), D55(=BURSA), D56(=CANAKKALE), } \\
\text { D57(=YALOVA) }\end{array}$ \\
\hline MA-13 & D58(=EDIRNE), D59(=KIRKLARELI), D60(=TEKIRDAG) \\
\hline MA-14 & D61(=ISTANBUL-ANATOLIAN PART) \\
\hline MA-15 & $\begin{array}{l}\text { D62(=SAKARYA), D63(=BOLU), D64(=DUZCE), } \\
\text { D65(=KOCAELI) }\end{array}$ \\
\hline MA-16 & $\begin{array}{l}\text { D66(=AFYON), D67(=BILECIK), D68(=ESKISEHIR), } \\
\text { D69(=KUTAHYA), D70(=USAK) }\end{array}$ \\
\hline MA-17 & D71(=ISTANBUL-EUROPEAN PART) \\
\hline MA-18 & D72(=KAYSERI) \\
\hline MA-19 & D73(=AYDIN), D74(=DENIZLI), D75(=MUGLA) \\
\hline MA-20 & D76(=ADIYAMAN), D77(=K. MARAS) \\
\hline MA-21 & $\begin{array}{l}\text { D78(=AMASYA }), \text { D79(=CORUM }), \text { D80(=ORDU }), \\
\text { D81(=SAMSUN), D82(=SINOP })\end{array}$ \\
\hline
\end{tabular}

Source: http://www.oib.gov.tr 
Map 1: Electricity Distribution Organisations and Proposed Merger Areas in Turkey

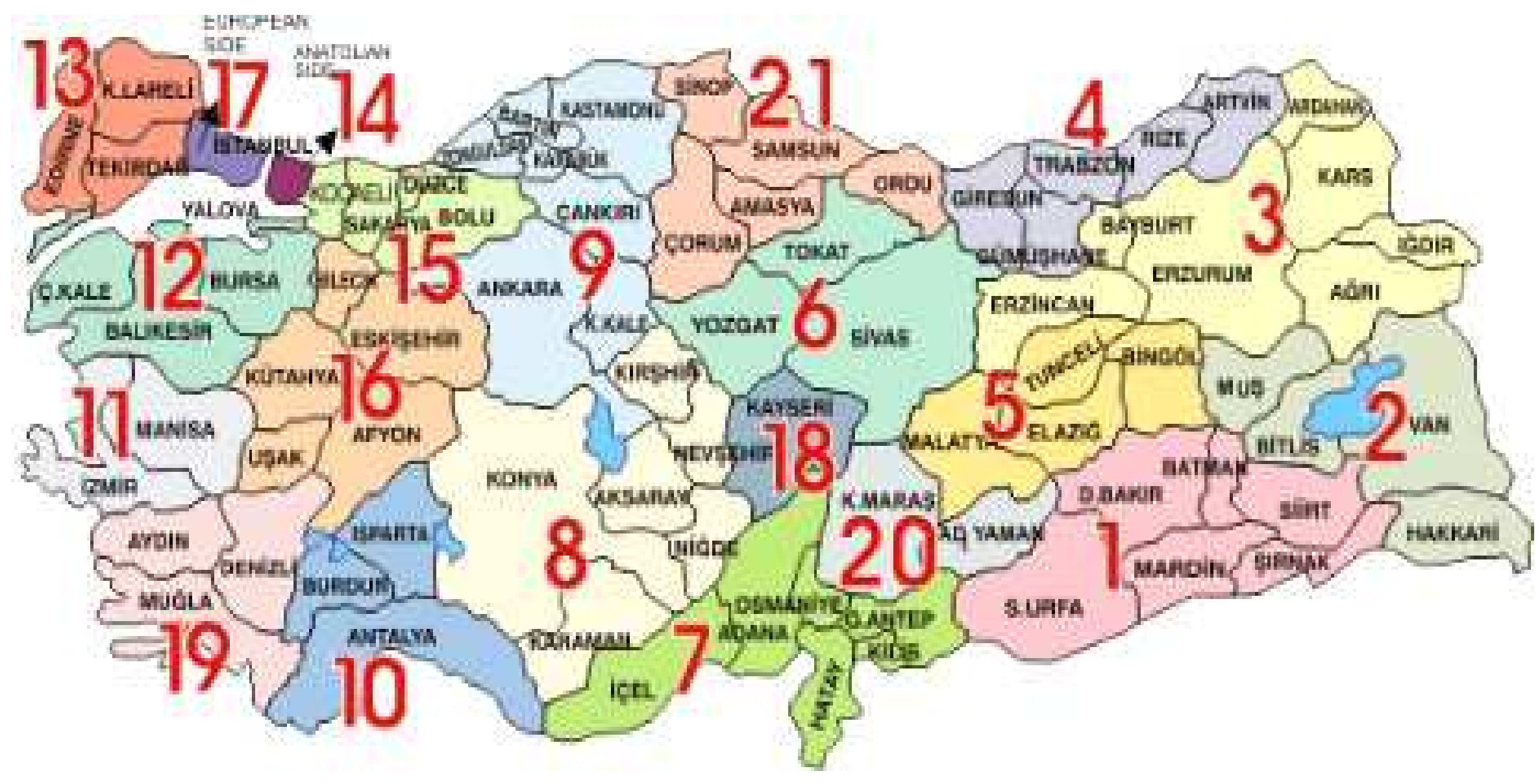

Source: $h t t p: / / w w w . o i b . g o v . t r$ 
According to the ESRPSP, the merger areas were determined with reference to the operational problems arising from geographical structure, the size of regions in terms of energy purchases, the technical and financial characteristics of the distribution organisations and the existing contracts. We do not know of any published document justifying or challenging the creation of these merged companies; a short unpublished document indicates that they were chosen to achieve cost minimisation and synergies, and to create an attractive market environment for international investors.

Our paper aims to fill this gap in explicit analysis by providing empirically based evidence of potential efficiency gains from these proposed mergers. The following section describes how we use the data envelopment methodology and measure the potential efficiency gains from these proposed mergers in the Turkish electricity distribution sector.

\section{THE DEA MODEL OF THE GAINS FROM MERGERS OF PRODUCTION UNITS}

The analysis of merger potential exploits the concept of sub-additivity of the cost function, and we begin by setting out the assumptions about the relevant technology. Outputs and inputs are real, non-negative values of vectors of non-random numbers, $\mathbf{x}$ and $\mathbf{y}$, respectively. We define a production set describing how $l$ outputs, $\mathbf{y} \in \mathrm{R}_{+}^{l}$, are made by $m$ inputs $\boldsymbol{x} \in R_{+}^{m}$

$$
T(x, y)=\{(x, y): x \text { can make } \boldsymbol{y}\}
$$

From this we can define an equivalent representation of the technology, the input requirement set $I(y)$

$$
I(y)=\{x: x \in T(x, y) \text { for given } y\}
$$

We shall assume throughout the paper that these representations of the technology have the properties of convexity and free disposability. These assumptions ensure 
that convex combinations of feasible input-output baskets are also feasible; that inputs are not congested in the sense that using more of one input requires use of more of the other inputs; and that none of the outputs is undesirable. Assumptions concerning returns to scale of the technology are critical for the analysis of mergers and are considered in more detail below. First, however, we note that Bogetoft and Wang emphasise the importance of additivity assumptions in the analysis. Fundamentally, it is assumed that:

$$
\left(\mathbf{x}^{0}+\mathbf{x}^{1}, \mathbf{y}^{0}+\mathbf{y}^{1}\right) \in T \text { if }\left(\mathbf{x}^{0}, \mathbf{y}^{0}\right) \in T, \text { and }\left(\mathbf{x}^{1}, \mathbf{y}^{1}\right) \in T
$$

Moreover, Bogetoft and Wang also assume J-additivity, which states that the above property is assumed to hold for any subset containing $J$ of the $n$ observations in the piecewise linear representation of the production set $T$. The essential point is that any merger is technically feasible even if not beneficial and that a merged utility can be operated as two independent divisions. Examination of the data on electricity distribution utilities in many European countries and elsewhere indicates that utilities that are smaller and larger than those in the Turkish sample are technically feasible. In particular, in the UK five of the current 14 electricity distribution utilities operate as independent divisions of merged firms. Consequently, we argue that the additivity and J-additivity assumptions are relatively innocuous. In particular they do not assume that mergers are beneficial, which is the empirical focus of the paper.

Given a set of exogenous input prices, $\boldsymbol{w}$, the cost function of a producer is:

$$
C(\mathbf{y}, \mathbf{w})=\min _{\mathbf{x}}\left(\mathbf{w}^{\prime} \mathbf{x}:(\mathbf{x}, \mathbf{y}) \in I(\mathbf{y})\right)
$$

A merger of $J$ producers (from amongst a total of $N$ producers) is potentially advantageous if the cost function is sub-additive:

$$
C\left(\sum_{j=1}^{J} \mathbf{y}^{j}, \mathbf{w}\right) \leq \sum_{j=1}^{j=J} C\left(\mathbf{y}^{j}, \mathbf{w}\right)
$$

This result, [4], states that the cost of manufacturing the sum of the merged outputs is less than or equal to the aggregate cost of producing the individual outputs. For given input prices, common to all producers, the sub-additivity result in [4] implies and is implied by super-additivity of the input requirements set, i.e. that the aggregate input 
requirements of the producers before the merger form a subset of the input requirements of the merged group.

$$
I\left(\sum_{j=1}^{J} \mathbf{y}^{j}\right) \subseteq \sum_{j=1}^{j=J} I\left(\mathbf{y}^{j}\right)
$$

Färe, Grosskopf and Lovell (1994, 263-9) demonstrate the duality analysis of mergers as shown in figure 2 .

Figure 2: Cost sub-additivity and input requirements super-additivity

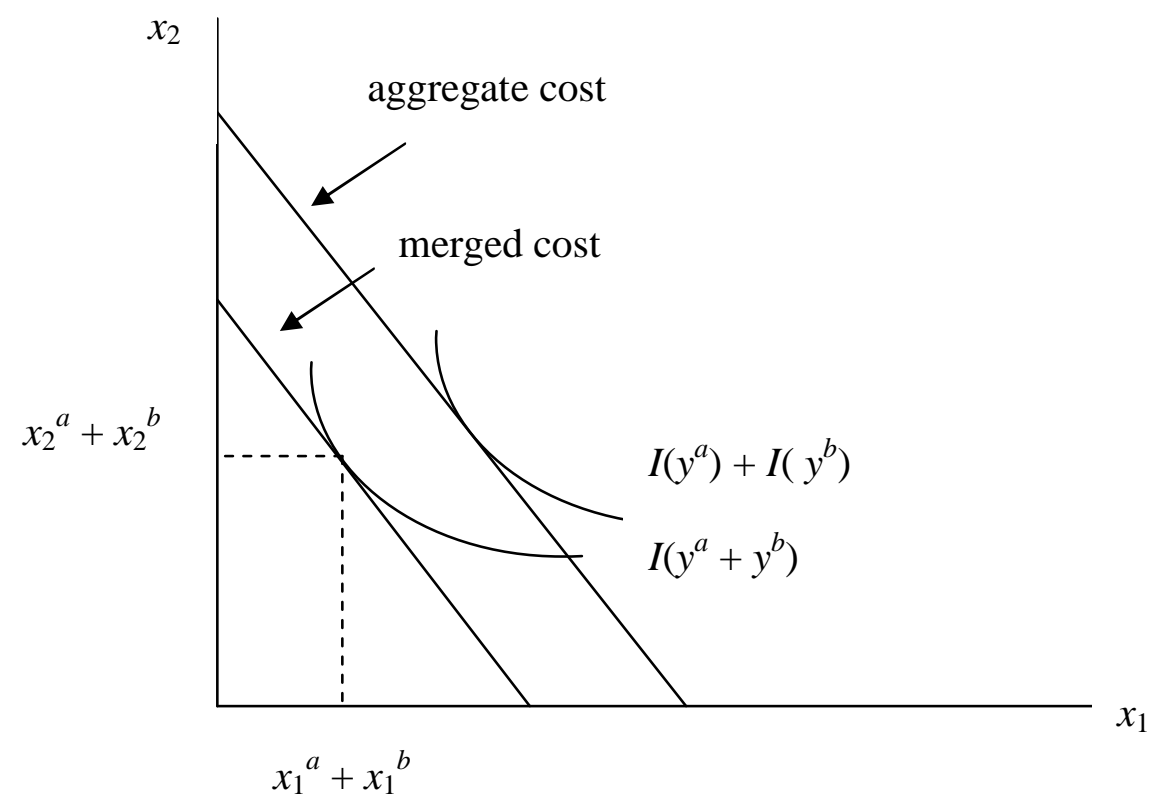

Figure 2 illustrates two producers, $a$ and $b$, using two inputs: $x_{1}$ and $x_{2}$ to produce a single output $y$. The input requirements set for each individual producer is $I(y)$, and its boundary is the firm's isoquant. The aggregate of the individual producers' outputs has input requirements: $I\left(y^{a}\right)+I\left(y^{b}\right)$, and for given input prices, $\mathbf{w}=\left(w_{1}, w_{2}\right)$, the aggregate cost of output is $C\left(y^{a}, \mathbf{w}\right)+C\left(y^{b}, \mathbf{w}\right)$. Cost sub-additivity will (weakly) justify a merger if the merged cost is not more than the aggregate individual costs. Formally, we write:

$$
C\left(y^{a}+y^{b}, \mathbf{w}\right) \leq C\left(y^{a}, \mathbf{w}\right)+C\left(y^{b}, \mathbf{w}\right)[6]
$$

This is illustrated in figure 2 where the merged cost is represented by the isocost line passing through the point: $\left(x_{1}^{a}+x_{1}^{b}\right),\left(x_{2}^{a}+x_{2}^{b}\right)$, and tangential to the isoquant boundary of the merged input requirements set: $I\left(y^{a}+y^{b}\right)$. From figure 2 we can see 
that cost-subadditivity is therefore equivalent by duality to super-additivity of the input requirements sets:

$$
I\left(y^{a}\right)+I\left(y^{b}\right) \subseteq I\left(y^{a}+y^{b}\right)
$$

This follows because the aggregated input requirement to produce at the minimum cost along $I\left(y^{a}\right)+I\left(y^{b}\right)$ clearly exceeds $\left(x_{1}^{a}+x_{1}^{b}\right),\left(x_{2}^{a}+x_{2}^{b}\right)$ as shown in figure 2. The Bogetoft and Wang (2005) model used in this paper evaluates mergers by calibrating the super-additivity of the piecewise linear representations of the inputs requirements sets with and without mergers. This allows us to evaluate mergers without requiring input price data. We are assuming in effect that all the service providers face the same input prices at any given time. This assumption is realistic for the 81 publicly owned Turkish electricity distribution companies, whose inputs are obtained by law through a common, publicly operated procurement policy.

We investigate a merger as a collection of firms for which the inputs and outputs have been combined. Assume that $J$ of the $N$ firms are merged, and arbitrarily re-labelled $k=1 \ldots J$ within the merged group. A merged group, i.e. what Färe et al (1994) call an out-of-sample or hypothetical firm, has the inputs and outputs:

$$
\begin{aligned}
& \tilde{x}_{i}^{J}=\sum_{k=1}^{k=J} x_{i k}, \quad i=1 \ldots m \\
& \tilde{y}_{r}^{J}=\sum_{k=1}^{k=J} y_{r k}, \quad r=1 \ldots l
\end{aligned}
$$

The objective is to compute measures of Overall Merger Efficiency, $E^{J}$, and to decompose this into constituent components. First, we calculate an input-orientated radial measure of overall merger efficiency, $E^{J}$, to evaluate the relative efficiency of a proposed merger of $J$ producers, subject to constraints which define a piecewise linear representation of the input requirements set. A piecewise linear representation of the input requirements set is based on observations of the input and output vectors of the $N$ producers, collected in the matrices: $\mathbf{X}$ and $\mathbf{Y}$, and a set of non-negative intensity weights, $\square$ :

$$
I^{P L R}(\mathbf{y})=\{\mathbf{x}: \mathbf{X} \lambda \leq \mathbf{x}, \mathbf{Y} \lambda \geq \mathbf{y}, \lambda \geq \mathbf{0}, \text { for given } \mathbf{y}\}
$$

Subsequently we make use of the vectors: $\mathbf{s}^{-}, \mathbf{s}^{+}$to represent the input and output slack variables in [10]. 
The overall evaluation of merger efficiency uses the aggregated inputs and outputs from [8] and [9] in the model:

$$
\begin{aligned}
& \min E^{J} \quad \text { s.t. } \\
& \sum_{j=1}^{j=N} \lambda_{j} x_{i j} \leq E^{J} \tilde{x}_{i}^{J}, i=1 \ldots m \\
& \sum_{j=1}^{j=N} \lambda_{j} y_{r j} \geq \tilde{y}_{r}^{J}, r=1 \ldots l \\
& \lambda_{j} \geq 0
\end{aligned}
$$

This suggests the merger is advantageous if $E^{J}<1$, i.e. the merged group could produce the same aggregate outputs with less input usage, and it is disadvantageous if $E^{J} \geq 1$.

The key to understanding the model's results is that we measure only the potential for efficiency gains. To achieve the gains which the model demonstrates are possible, appropriate incentive mechanisms would need to be in place. The model does not guarantee that the gains will necessarily be achieved by the indicated merger. It states only that there is a potential gain to the merger arising from the measured inefficiency of the aggregated producers. If no such inefficiency exists either because the producers are already efficient, or because the merged group is infeasibly large for the reference technology, then the merger is not advantageous. If inefficiency of the feasible merged group is observed, relative to the chosen reference technology, then the merger may be beneficial if it can be accompanied by incentives designed to drive out the inefficiencies. In the absence of the relevant incentives, the merger will probably fail to achieve its potential. The test embodied in the model tells the investigator whether there could be a positive return to better incentive design within a merged group of producers.

The specification of returns to scale of the reference technology is important in the evaluation of the merger possibilities because by definition a merged group of producers is a rescaling of the individual producers in the group. A variety of cases is possible for the piecewise linear representation of the input requirements set depending on the properties of the intensity weights. The three which will be of interest in this input orientation are constant, variable and non-increasing returns to scale, respectively: crs, vrs, and nirs. 
For constant returns to scale, crs, the piecewise linear representation requires: $\lambda_{j} \geq 0, j=1 \ldots N$; for variable returns to scale, vrs, the requirement is $\lambda_{j} \geq 0, j=1 \ldots N$, and $\sum_{j=1}^{j=N} \lambda_{j}=1$, while for non-increasing returns to scale, nirs, the requirement is: $\lambda_{j} \geq 0, j=1 \ldots N$, and $\sum_{j=1}^{j=N} \lambda_{j} \leq 1$. These technologies are nested, with the vrs reference technology being a subset of the nirs reference technology, and the nirs being a subset of the crs reference technology ${ }^{7}$.

Bogetoft and Wang (2005, proposition 1) demonstrate that a crs reference technology has the necessary and sufficient conditions to ensure that $E^{J} \leq 1$ for arbitrary mergers. However for a vrs reference technology, these conditions may not hold and it is possible that there will be no feasible solution to the linear programme defined by [11]. That would not of course imply that the merger itself was infeasible in a practical sense. Infeasibility of the non-parametric programme [11] would signify that the merged output vector was too large to be feasible relative to the chosen reference technology, or that the merged inputs vector could not be made available by combining the observed inputs in a feasible way, i.e. by non-negative intensity weights which summed to unity.

The concept of scale effects used here is related to the properties of the production set. This contrasts with the specification of the production function in an econometric approach - indeed there is no assumption that a parametrically specified production or transformation function exists. The production set may exhibit properties of crs or $v r s$, more specifically nirs or non-decreasing returns to scale (ndrs) for different ranges of the sample of observations. In moving from a low-scale firm to a high-scale firm the efficient frontier that envelopes the firms may expand more than proportionately (ndrs), proportionately ( $c r s)$ or less than proportionately (nirs). If all the expansion possibilities are proportional then the technology exhibits crs, while if the expansion possibility becomes limited at high scale levels, then the reference technology exhibits nirs and some mergers may be infeasible. Since the specification

\footnotetext{
${ }^{7}$ The crs reference technology is a convex cone containing the observed points in input-output space, while the vrs reference technology is the convex hull of the observed points.
} 
of a crs or vrs technology is open to the researcher, both possibilities can be measured, allowing for mergers which are feasible under one specification but may not be feasible under the other. This contrasts with the econometric approach where the wrong specification leads to inconsistent estimates of the parameters. By carrying out a test of the distribution functions of the efficiency scores, the researcher can infer which assumption is valid for the sample under consideration.

In this paper we are investigating a set of planned mergers comprising a wide range of different service producers. Consequently we can think of the range of potential mergers as comprising a blue-print for the organisational structure of the industry. In principle any subset of the potential mergers may be evaluated as a potential candidate for implementation, and the implementation has the characteristics of a long run decision with no pre-determined factors. This strongly suggests that for overall merger efficiency measurement, the crs reference technology is the appropriate benchmark. This is the one on which we focus for overall merger efficiency, although we also calculate the vrs case to check for programme infeasibility.

Bogetoft and Wang (2005) suggest a decomposition of the overall merger efficiency into three components, the individual technical efficiency effect, $T^{J}$, a harmony, scope or mixture effect, $H^{J}$, and a scaling or size effect, $S^{J}$. The decomposition is multiplicative:

$$
E^{J}=T^{J} \times H^{J} \times S^{J}
$$

The individual technical efficiency effect adjusts the merged inputs for potential efficiency gains within the group as each member is given incentives to reach the frontier for the group. Within the merged group, therefore, the relative efficiency of each of the merging firms could be computed with reference to the rest of the group by the data envelopment analysis model. For example in the vrs case, we have:

$$
\begin{aligned}
& \min E^{o} \quad \text { s.t. } \\
& \sum_{k=1}^{k=J} \lambda_{k} x_{i k} \leq E^{o} x_{i o}, i=1 \ldots m, o=1, \ldots J \\
& \sum_{k=1}^{k=J} \lambda_{k} y_{r k} \geq y_{r o}, r=1 \ldots l \\
& \lambda_{k} \geq 0 ; \sum_{k=1}^{k=J} \lambda_{k}=1
\end{aligned}
$$


In principle this model could be computed under any of the returns to scale assumptions, but no issue of programme infeasibility arises since each of the right hand side inputs and outputs is already an observed member of the set merged inputs and outputs.

Applying this in turn to each of the merged firms in the group suggests how the inputs could be adjusted as part of the merger to bring each firm up to the frontier of the group by multiplying the inputs by the relative input efficiencies, $E^{k}, k=o=1 \ldots J$. This in turn provides a new set of merged group inputs after the efficiency adjustment:

$$
E \tilde{x}_{i}^{J}=\sum_{k=1}^{k=J} E^{k} x_{i k}, i=1 \ldots m
$$

In this paper we compute this model for each of the three returns to scale assumptions, but in presenting the results we concentrate on the vrs case shown in [13]. Our argument is that, unlike the situation when we are contemplating the range of potential mergers which is analogous to a long-run blueprint for the industry, within each actual merger there will be short-run difficulties and adjustments in forging a united group. The preferences and customs of the individual agents amongst other factors will add to this difficulty, and consequently it is more appropriate to adopt a less flexible reference technology when computing the within merger efficiencyadjusted inputs. Using these within merger efficiency-adjusted inputs, we re-compute the overall merger efficiency model:

$$
\begin{aligned}
& \min E^{*^{J}} \quad \text { s.t. } \\
& \sum_{j=1}^{j=N} \lambda_{j} x_{i j} \leq E^{*^{J}}\left(E \tilde{x}_{i}^{J}\right), i=1 \ldots m \\
& \sum_{j=1}^{j=N} \lambda_{j} y_{r j} \geq \tilde{y}_{r}^{J}, r=1 \ldots l \\
& \lambda_{j} \geq 0
\end{aligned}
$$

The first element in the decomposition is then

$$
T^{J}=E^{J} / E^{* J}
$$

Consequently, the individual technical efficiency effects index is a radial measure of the component of overall merger efficiency which can be attributed to the effect on each of the members of the merged group of achieving the frontier efficiency of the group. 
The second component of the decomposition identified by Bogetoft and Wang (2005) is an economies of scope effect. However this does not arise from the merger of producers with different output portfolios in the textbook sense of economies of scope, but rather from the merger of different input mixes in producing a given range of outputs. The merged group can adopt an input mix which is intermediate amongst the different input mixes of the individual members. In effect it is exploiting the convexity of the piecewise linear representation of the isoquant boundary of the input requirements set. Using the indicator $H^{J}$ to measure the mixture effect, values of the indicator $H^{J}<1$ state that harmonising the input mix within the merged groups will improve efficient merger performance, and values $H^{J}>1$ state that the problem of harmonising very different input mixes will detract from merger performance. Bogetoft and Wang (2005) compute this effect by comparing an average of the merged producers with the reference technology; the purpose is to calculate for the merged group how much of the average input could have been saved in the production of the average output', Bogetoft and Wang $(2005,155)$. The required programme is:

$$
\begin{aligned}
& \min H^{J} \quad \text { s.t. } \\
& \sum_{j=1}^{j=N} \lambda_{j} x_{i j} \leq H^{J}\left[\left(E \tilde{x}_{i}^{J}\right) / J\right], i=1 \ldots m \\
& \sum_{j=1}^{j=N} \lambda_{j} y_{r j} \geq\left[\tilde{y}_{r}^{J} / J\right], r=1 \ldots l \\
& \lambda_{j} \geq 0
\end{aligned}
$$

Applying programmes [15] and [17] to the merged groups has adjusted the overall merger efficiency for both individual technical efficiency effects within the merged group, and for efficiency improvements that would arise if the mean input-output basket of the merged producers was available as an out-of-sample observation.

We have isolated two effects that account for technical efficiency and scope efficiency gains from a merger. Bogetoft and Wang (2005) argue that any remaining efficiency gains must be due to scale efficiency. This reflects the fact that the merged group will be able to take advantage of its size relative to other producers to exploit any remaining returns to scale. This effect may be opposite to the other efficiency gains if the industry generally is subject to decreasing returns to scale, signalled for 
example by the component producers each having decreasing returns to scale. The scale effect is computed as a residual after adjusting merged inputs for technical efficiency and scope or harmony effects. It is measured relative to a reference technology which may exhibit any of the three scale assumptions embodied in crs, vrs, nirs. It is shown by the model in [18] below.

$$
\begin{aligned}
& \min S^{J} \quad \text { s.t. } \\
& \sum_{j=1}^{j=N} \lambda_{j} x_{i j} \leq S^{J}\left[H^{J}\left(E \tilde{x}_{i}^{J}\right)\right], i=1 \ldots m \\
& \sum_{j=1}^{j=N} \lambda_{j} y_{r j} \geq \tilde{y}_{r}^{J}, r=1 \ldots l \\
& \lambda_{j} \geq 0
\end{aligned}
$$

Care needs to be exercised in distinguishing these components of the decomposition of overall merger efficiency since each follows in a sequence of prior adjustments to the out-of-sample data representing the merged group.

The dual to each envelopment model is a multiplier model with dual variables which are the components of the marginal rates of substitution and transformation between inputs and outputs. By the complementary slackness theorem of linear programming, we know that positive slacks in the envelopment input and output constraints are associated with zero values for the corresponding input and output multiplier weights in the dual to the DEA programme:

$$
\begin{aligned}
& u_{r} s_{r}^{+}=0, r=1 \ldots l \\
& v_{i} s_{i}^{-}=0, i=1 \ldots m
\end{aligned}
$$

Consequently, we can identify positive multiplier weights with input and output dimensions in which each distribution service is fully constrained, and therefore we can identify the absent inputs and outputs as ones where there are positive slacks.

As shown above the Bogetoft and Wang model provides a useful identification of the presence and extent of potential efficiency gains from mergers, which could be used in a merger review by a competition - or any other regulatory - authority. In the following section we apply this model to identify the presence and extent of such gains in the proposed mergers from Turkish electricity distribution. 


\section{DATA AND RESULTS}

The data we use comprise a panel of annual data from 1999-2003 of 82 electricity distribution utilities in Turkey. The source of the data is the MENR. The variables used and their descriptive statistics are shown in table 2:

Table 2: Descriptive Statistics of 82 Turkish Electricity Distributors

\begin{tabular}{|l|r|r|r|r|}
\hline \multicolumn{1}{|c|}{1999} & \multicolumn{1}{c|}{ Mean } & Standard Deviation & Minimum & Maximum \\
\hline $\mathrm{y}_{1}:$ numbers of customers & 279701 & 399998 & 25775 & 2886336 \\
\hline $\mathrm{y}_{2}:$ electricity consumed (MWh) & 868514 & 1545449 & 32827 & 11001899 \\
\hline $\mathrm{y}_{3}:$ service area (square kilometres) & 9450 & 6376 & 840 & 38257 \\
\hline $\mathrm{x}_{1}:$ numbers of employees & 424 & 431 & 62 & 2547 \\
\hline $\mathrm{x}_{2}:$ numbers of transformers & 1667 & 1181 & 283 & 5852 \\
\hline $\mathrm{x}_{3}:$ transformer capacity (MVA) & 501 & 967 & 35 & 7757 \\
\hline $\mathrm{x}_{4}:$ network length (kilometres) & 8121 & 6322 & 1038 & 32182 \\
\hline $\mathrm{x}_{5}:$ network losses $(\mathrm{MWh})$ & 217622 & 416557 & 7679 & 3123155 \\
\hline Percentage losses $\left(100 * \mathrm{x}_{5} / \mathrm{y}_{2}\right)$ & $26 \%$ & & & \\
\hline
\end{tabular}

\begin{tabular}{|l|r|r|r|r|}
\hline \multicolumn{1}{|c|}{2000} & \multicolumn{1}{|c|}{ Mean } & Standard Deviation & Minimum & Maximum \\
\hline $\mathrm{y}_{1}:$ numbers of customers & 292825 & 417581 & 29480 & 2960792 \\
\hline $\mathrm{y}_{2}:$ electricity consumed (MWh) & 930047 & 1657026 & 38049 & 11665488 \\
\hline $\mathrm{y}_{3}:$ service area (square kilometres) & 9450 & 6376 & 840 & 38257 \\
\hline $\mathrm{x}_{1}:$ numbers of employees & 425 & 421 & 75 & 2489 \\
\hline $\mathrm{x}_{2}:$ numbers of transformers & 1725 & 1229 & 273 & 6053 \\
\hline $\mathrm{x}_{3}:$ transformer capacity (MVA) & 519 & 1007 & 40 & 7987 \\
\hline $\mathrm{x}_{4}:$ network length (kilometres) & 8634 & 6569 & 1074 & 33016 \\
\hline $\mathrm{x}_{5}:$ network losses $(\mathrm{MWh})$ & 246246 & 478634 & 6498 & 3614434 \\
\hline Percentage losses $\left(100 * \mathrm{x}_{5} / \mathrm{y}_{2}\right)$ & $26 \%$ & & & \\
\hline
\end{tabular}

\begin{tabular}{|l|r|r|r|r|}
\hline \multicolumn{1}{|c|}{2001} & \multicolumn{1}{c|}{ Mean } & Standard Deviation & Minimum & Maximum \\
\hline $\mathrm{y}_{1}:$ numbers of customers & 302449 & 433669 & 30340 & 3081424 \\
\hline $\mathrm{y}_{2}:$ electricity consumed (MWh) & 911835 & 1608932 & 40122 & 11239275 \\
\hline $\mathrm{y}_{3}:$ service area (square kilometres) & 9450 & 6376 & 840 & 38257 \\
\hline $\mathrm{x}_{1}:$ numbers of employees & 412 & 412 & 83 & 2544 \\
\hline $\mathrm{x}_{2}:$ numbers of transformers & 1775 & 1254 & 282 & 6226 \\
\hline $\mathrm{x}_{3}:$ transformer capacity (MVA) & 543 & 1036 & 40 & 8126 \\
\hline $\mathrm{x}_{4}:$ network length (kilometres) & 8990 & 6871 & 1086 & 33920 \\
\hline $\mathrm{x}_{5}:$ network losses $(\mathrm{MWh})$ & 238255 & 492887 & 5387 & 3738892 \\
\hline Percentage losses $\left(100 * \mathrm{x}_{5} / \mathrm{y}_{2}\right)$ & $26 \%$ & & & \\
\hline
\end{tabular}




\begin{tabular}{|l|r|r|r|r|}
\hline \multicolumn{1}{|c|}{2002} & \multicolumn{1}{|c|}{ Mean } & Standard Deviation & Minimum & Maximum \\
\hline $\mathrm{y}_{1}:$ numbers of customers & 313125 & 450082 & 32032 & 3171013 \\
\hline $\mathrm{y}_{2}:$ electricity consumed (MWh) & 941196 & 1719868 & 41276 & 12183956 \\
\hline $\mathrm{y}_{3}:$ service area (square kilometres) & 9450 & 6376 & 840 & 38257 \\
\hline $\mathrm{x}_{1}:$ numbers of employees & 406 & 429 & 75 & 2442 \\
\hline $\mathrm{x}_{2}:$ numbers of transformers & 1812 & 1294 & 176 & 6295 \\
\hline $\mathrm{x}_{3}:$ transformer capacity (MVA) & 561 & 1064 & 39 & 8234 \\
\hline $\mathrm{x}_{4}:$ network length (kilometres) & 9281 & 7170 & 1074 & 34080 \\
\hline $\mathrm{x}_{5}:$ network losses $(\mathrm{MWh})$ & 244954 & 487425 & 5080 & 3648242 \\
\hline Percentage losses $\left(100 * \mathrm{x}_{5} / \mathrm{y}_{2}\right)$ & $26 \%$ & & & \\
\hline
\end{tabular}

\begin{tabular}{|l|r|r|r|r|}
\hline \multicolumn{1}{|c|}{2003} & \multicolumn{1}{|c|}{ Mean } & Standard Deviation & Minimum & Maximum \\
\hline $\mathrm{y}_{1}:$ numbers of customers & 324643 & 468680 & 32317 & 3312396 \\
\hline $\mathrm{y}_{2}:$ electricity consumed $(\mathrm{MWh})$ & 1018520 & 1855079 & 42196 & 13152383 \\
\hline $\mathrm{y}_{3}:$ service area (square kilometres) & 9450 & 6376 & 840 & 38257 \\
\hline $\mathrm{x}_{1}:$ numbers of employees & 379 & 389 & 69 & 2117 \\
\hline $\mathrm{x}_{2}:$ numbers of transformers & 1838 & 1340 & 176 & 6494 \\
\hline $\mathrm{x}_{3}:$ transformer capacity (MVA) & 580 & 1118 & 39 & 8499 \\
\hline $\mathrm{x}_{4}:$ network length $($ kilometres) & 9384 & 7428 & 1108 & 35748 \\
\hline $\mathrm{x}_{5}:$ network losses $(\mathrm{MWh})$ & 250640 & 491490 & 4507 & 3393046 \\
\hline Percentage losses $\left(100 * \mathrm{x}_{5} / \mathrm{y}_{2}\right)$ & $25 \%$ & & & \\
\hline
\end{tabular}

We designate output variables as $\mathrm{y}_{\mathrm{r}}$, and input variables as $\mathrm{x}_{\mathrm{i}}$. All of the variables are measured in levels because ratios of variables may raise interpretative issues for the question of returns to scale. We adopt an input orientation because we recognise that utilities will be constrained to minimise input usage subject to meeting exogenous output targets. The outputs are customer service, which is proxied by the numbers of customers served by each distribution utility, and electricity distributed. Service area in the case of these utilities is an exogenous variable. However it can be regarded in this context also as a non-discretionary output since it represents an additional target for service level coverage. In the input orientation used here, therefore, service area will appear as indistinguishable from the other outputs rather than as an output that can be priced in an economically meaningful sense (Neuberg, 1977). The capital infrastructure to supply this range of services consists of transformers and network length, and this is supplemented by labour input. In reinforcing a network, electricity losses will rise as service area expands unless additional physical capital is used. Consequently, we are able to use electrical losses as another form of input to proxy 
the direct capital requirements of improving the quality of the network. The model is similar in concept to Bagdadioglu, Waddams Price and Weyman-Jones (1996).

In computing the linear programmes we expressed all data in mean corrected form using the panel mean for each variable ${ }^{8}$. This has the advantage of removing major differences in the absolute size of the dimensions and units of the variables. The radial efficiency measures that we shall use are unit invariant, so results are not affected by dividing each variable by its panel mean. The availability of a panel of data allows us to improve the interpretation of the results in two ways. First, we are able to compare the consistency of the findings about merger efficiency across different years in a period during which the distribution service was undergoing major changes. Secondly, we are able to apply the suggestion of Ruggiero (2004) that using data on inputs and outputs that have been averaged over a number of periods reduces the problem of measurement error. Consequently we have the choice of six datasets on which to evaluate the mergers: each of the years 1999-2003 separately, and the average of the years 1999-2003. In computing the mergers' efficiency gains it is this last, average over all years, on which we concentrate. However, we first tested whether any of the individual years 1999 through to 2003 gave different results from the pooled sample average by applying non-parametric Kolmogorov-Smirnov (K-S) tests of the equality of the efficiency (and log efficiency) scores distribution functions for individual years with the sample average. All of the high K-S p-values (1999: 0.98, 2000: $0.98,2001: 0.93,2002: 1.00,2003: 0.83)$ strongly indicate that there is no difference in the efficiency distribution functions for individual years and the pooled sample average which we have used.

While the full model described above is used in the efficiency calculations for this paper, it is important to consider other specifications ${ }^{9}$. Standard variables for the outputs are numbers of customers and electricity delivered to reflect the customer service and energy consumption objectives of the utilities (Estache, Rossi, and Ruzzier, 2002, and Jamasb and Pollitt, 2001). However, on the output side, the full model also includes service area as an output variable to reflect the difficulty of

\footnotetext{
${ }^{8}$ All of the linear programmes for the data envelopment analysis and the merger evaluations were written in GAMS (General Algebraic Modelling System) software.

${ }^{9} \mathrm{We}$ are grateful to an anonymous referee for reminding us of this.
} 
meeting customer services over a less densely populated area. As the table of descriptive statistics shows, service areas vary markedly from $840 \mathrm{~km}^{2}$ to over 38,000 $\mathrm{km}^{2}$. This specification is tested using a non-parametric K-S test applied to the constant returns to scale specification with the full vector of inputs ${ }^{10}$. The results are open to different interpretations. The K-S test fails to reject the null that the efficiency distribution functions are equal with and without service area at the 5 per cent level of significance, $(\mathrm{K}-\mathrm{S}$ p-value $=0.059)$ but does reject the null that the efficiency scores are not lower when service area is excluded, $(\mathrm{K}-\mathrm{S} \mathrm{p}$-value $=0.029)$. This tells us that while the utilities will always show higher efficiency scores when service area is included, the efficiency scores are not different at the 5 per cent level of significance. It could be argued therefore that whether service area is included or not will not affect the distribution of efficiency scores. We would get lower but not significantly different efficiency scores by excluding the service area, but at the expense of penalising utilities with large service areas by suggesting that they are less efficient than the case when service area is included. This would have the effect of suggesting that there are greater potential efficiency gains to mergers of utilities serving large areas than is the case when service area is included. This could impact strongly on the analysis of mergers, so it becomes a matter of judgement about which model to prefer. It can be argued that service area should be included if the utilities' efficiency scores are to be shown in the best light before the merger calculations. This prompts us to keep service area in the model in order not to over-estimate the potential gains from mergers of utilities which already serve geographically large areas.

On the input side, number of employees, transformer capacity and network length are standard inputs used in virtually all regulatory jurisdictions (Estache, Rossi, and Ruzzier, 2002; Jamasb and Pollitt, 2001). The analysis includes the number of transformers, and also the level of electricity losses as a measure of input requirements for line reinforcement. We tested the specification of the input vectors as: $\left(\mathrm{x}_{1}, \mathrm{x}_{2}, \mathrm{x}_{3}, \mathrm{x}_{4}, \mathrm{x}_{5}\right)$ against $\left(\mathrm{x}_{1}, \mathrm{x}_{3}, \mathrm{x}_{4}, \mathrm{x}_{5}\right),\left(\mathrm{x}_{1}, \mathrm{x}_{2}, \mathrm{x}_{3}, \mathrm{x}_{4}\right)$, and $\left(\mathrm{x}_{1}, \mathrm{x}_{3}, \mathrm{x}_{4}\right)$. In all cases the $\mathrm{K}-\mathrm{S}$ p-values $(0.71,0.98$, and 0.25 respectively) fail to reject the null that the efficiency score distribution functions are equal. Consequently, by using the full

\footnotetext{
${ }^{10}$ Cumulative distribution functions of both the $\log$ of efficiency as suggested by Banker and Natarajan (2004), and the level of efficiency are used; the results are identical in all of the K-S tests.
} 
vector of outputs, we are able to show the pre-merger utilities in the best light, without using a specification which yields efficiency scores that differ significantly from any of the other competing specifications that were considered. In summary, at the 5 per cent level of significance, the efficiency scores are not sensitive to output and input specifications that differ from the full model used in the remainder of the paper.

In table 3, we report the DEA efficiency scores for each of the 82 distribution utilities under the crs assumption. We also identify the efficient peers for each of the utilities. The brackets in the first column show for how many inefficient distributors each efficient distributor is the reference organisation. Table 3 also indicates which of the outputs and inputs have positive dual multiplier weights, and consequently allows us to infer those variables for which each utility experiences slack. These are shown as “-” in the relevant column for each organisation. Finally, table 3 indicates the nature of the returns to scale region in which each utility operates, and the degree of scale efficiency. 
Table 3: The Mergers Efficiency Gains - The Pooled Average of 1999-2003

\begin{tabular}{|c|c|c|c|c|c|c|c|c|c|c|c|c|}
\hline \multirow[t]{2}{*}{ EDO } & \multirow{2}{*}{$\begin{array}{c}\text { TE } \\
(\mathbf{C R S})\end{array}$} & \multirow[t]{2}{*}{ Peers } & \multicolumn{8}{|c|}{ Dual Multiplier Weight } & \multirow{2}{*}{$\begin{array}{c}\text { RTS } \\
\text { Region }\end{array}$} & \multirow{2}{*}{$\begin{array}{c}\text { Scale } \\
\text { Efficienc } \\
y\end{array}$} \\
\hline & & & Y1 & Y2 & Y3 & X1 & $\mathrm{X} 2$ & X3 & X4 & X5 & & \\
\hline D1 & 0.606 & D4, D27, D59, D68, D69, D71 & 0.178 & 0.087 & 0.231 & 0.231 & 0.004 & 0.005 & 0.429 & - & drs & 0.984 \\
\hline D2 & 0.637 & D4, D6, D17, D27, D59 & 0.119 & 0.185 & 0.513 & 0.292 & 0.001 & - & 1.084 & - & drs & 0.997 \\
\hline D3 & 0.696 & D16, D67, D77 & - & 1.278 & 0.693 & - & 1.197 & 2.874 & - & - & irs & 0.996 \\
\hline D4 (2) & 1.000 & D4 & 0.306 & 0.148 & 0.291 & 0.748 & - & - & 0.318 & - & crs & 1.000 \\
\hline D5 & 0.650 & D17, D59, D71 & 0.121 & 0.558 & 0.886 & - & - & - & 2.886 & - & $\mathrm{drs}$ & 0.990 \\
\hline D6 (5) & 1.000 & D6 & 0.089 & 0.874 & 1.022 & - & 3.532 & - & - & - & crs & 1.000 \\
\hline D7 & 0.734 & D17, D27 & - & - & 1.035 & 0.441 & - & - & 2.013 & - & $\mathrm{drs}$ & 0.998 \\
\hline D8 & 0.755 & D6, D16, D17, D27 & - & - & 1.001 & 0.334 & 0.991 & 0.526 & 0.835 & - & $\mathrm{drs}$ & 0.947 \\
\hline D9 & 0.936 & D17, D27 & - & - & 1.079 & 0.460 & - & - & 2.101 & - & $\mathrm{drs}$ & 0.997 \\
\hline D10 & 0.861 & D6, D16, D17, D27 & - & - & 0.427 & 0.168 & 0.502 & - & 0.332 & 0.011 & $\mathrm{drs}$ & 0.887 \\
\hline D11 & 0.779 & D6, D16, D27, D59 & - & 0.526 & 0.545 & 1.026 & 0.633 & - & - & 0.015 & drs & 0.967 \\
\hline D12 (0) & 1.000 & D12 & 1.131 & - & 0.496 & 0.051 & 0.981 & - & - & 3.982 & crs & 1.000 \\
\hline D13 & 0.894 & D16, D17, D27, D59, D68 & 0.230 & 0.061 & 0.260 & - & 0.612 & - & 0.112 & 0.132 & drs & 0.925 \\
\hline D14 & 0.881 & D6, D16, D17, D27 & - & - & 0.882 & 0.348 & 1.039 & - & 0.686 & 0.023 & drs & 0.967 \\
\hline D15 (2) & 1.000 & D15 & - & - & 2.588 & 2.588 & - & - & - & 21.696 & crs & 1.000 \\
\hline D16 (10) & 1.000 & D16 & - & - & 1.695 & - & - & 14.026 & - & - & crs & 1.000 \\
\hline D17 (9) & 1.000 & D17 & 1.758 & 0.556 & 1.943 & - & 7.335 & - & - & - & crs & 1.000 \\
\hline D18 & 0.883 & D27, D41, D58, D69 & 1.278 & 0.510 & 0.568 & 2.359 & - & 1.145 & - & - & irs & 0.959 \\
\hline D19 & 0.969 & D69, D80 & 1.394 & - & - & - & - & 2.320 & - & 0.530 & irs & 0.994 \\
\hline D20 (2) & 1.000 & D20 & 3.906 & - & 0.323 & - & - & 1.158 & - & 16.101 & crs & 1.000 \\
\hline D21 & 0.771 & D54, D64, D69 & 1.516 & - & - & 0.919 & - & 1.408 & - & 0.067 & irs & 0.954 \\
\hline D22 & 0.838 & D61, D69 & 0.791 & - & - & - & 0.495 & 0.609 & - & - & $\mathrm{drs}$ & 0.959 \\
\hline D23 & 0.978 & D16, D26, D27 & 0.025 & - & 1.132 & - & - & 3.949 & 1.197 & - & irs & 0.991 \\
\hline D24 & 0.751 & D67, D69, D77 & 0.794 & 0.332 & - & - & - & 1.455 & 0.292 & - & irs & 0.998 \\
\hline D25 & 0.695 & D27, D58, D67, D69 & 0.332 & 0.315 & 0.145 & 0.548 & - & 0.626 & - & - & drs & 0.990 \\
\hline D26 (1) & 1.000 & D26 & - & - & 1.216 & - & - & 7.510 & - & 1.654 & crs & 1.000 \\
\hline D27 (22) & 1.000 & D27 & 0.253 & 0.119 & 0.245 & - & 0.700 & 0.003 & - & 0.253 & crs & 1.000 \\
\hline D28 & 0.839 & $\mathrm{D} 20, \mathrm{D} 69, \mathrm{D} 80$ & 1.181 & - & 0.020 & - & - & 2.159 & 0.037 & - & irs & 0.999 \\
\hline D29 & 0.940 & D27, D54, D58, D69 & 0.648 & - & 0.367 & 1.056 & 0.389 & - & - & 0.007 & irs & 0.998 \\
\hline
\end{tabular}




\begin{tabular}{|c|c|c|c|c|c|c|c|c|c|c|c|c|}
\hline \multirow[t]{2}{*}{ EDO } & \multirow{2}{*}{$\begin{array}{c}\text { TE } \\
(\mathrm{CRS})\end{array}$} & \multirow[t]{2}{*}{ Peers } & \multicolumn{8}{|c|}{ Dual Multiplier Weight } & \multirow{2}{*}{$\begin{array}{c}\text { RTS } \\
\text { Region }\end{array}$} & \multirow{2}{*}{$\begin{array}{c}\text { Scale } \\
\text { Efficienc } \\
\mathbf{y}\end{array}$} \\
\hline & & & Y1 & Y2 & Y3 & X1 & $\mathrm{X} 2$ & X3 & $\mathbf{X 4}$ & X5 & & \\
\hline D30 & 0.779 & D61, D69 & 0.382 & - & - & - & 0.239 & 0.294 & - & - & drs & 0.960 \\
\hline D31 & 0.769 & D41, D54, D58, D61 & 0.290 & - & 0.124 & 0.534 & - & 0.001 & 0.067 & - & drs & 0.989 \\
\hline D32 & 0.966 & D61, D69 & 2.252 & - & - & - & - & - & 2.097 & 2.362 & irs & 0.966 \\
\hline D33 & 0.778 & D54, D61, D69 & 0.535 & - & - & 0.031 & 0.313 & 0.403 & - & - & crs & 1.000 \\
\hline D34 (0) & 1.000 & D34 & - & 0.437 & 0.082 & 0.524 & - & 0.390 & - & - & crs & 1.000 \\
\hline D35 & 0.751 & D61, D69 & 6.201 & - & - & - & - & 4.712 & 4.466 & - & irs & 0.751 \\
\hline D36 & 0.823 & D16, D27, D69 & 1.047 & - & 0.727 & - & 2.084 & - & - & 0.917 & irs & 0.925 \\
\hline D37 & 0.801 & D52, D67, D69 & 1.079 & 0.741 & - & - & 1.035 & - & - & 2.803 & irs & 0.984 \\
\hline D38 & 0.735 & D27, D59, D67, D68, D69 & 0.318 & 0.315 & 0.594 & 0.440 & - & - & 1.273 & 0.247 & irs & 0.977 \\
\hline D39 & 0.743 & D16, D27, D69 & 0.747 & - & 0.519 & - & 1.487 & - & - & 0.654 & irs & 0.977 \\
\hline D40 & 0.859 & D27, D67, D68, D69 & 0.121 & 0.058 & 0.118 & - & 0.336 & - & - & 0.126 & drs & 0.859 \\
\hline D41 (9) & 1.000 & D41 & 0.491 & 1.119 & 0.586 & - & 1.047 & - & - & 5.191 & crs & 1.000 \\
\hline D42 & 0.774 & D16, D59, D61, D68, D69 & 0.089 & 0.027 & 0.071 & - & 0.213 & 0.006 & - & 0.063 & drs & 0.774 \\
\hline D43 & 0.794 & D59, D61, D65, D69 & 1.839 & 0.213 & 0.141 & - & 1.476 & 1.532 & - & - & irs & 0.900 \\
\hline D44 & 0.974 & D59, D60, D69 & 0.858 & 0.282 & - & - & - & 1.159 & 0.526 & - & drs & 0.998 \\
\hline D45 & 0.810 & D54, D61, D69 & 2.771 & - & - & 2.411 & - & - & 0.469 & 2.034 & irs & 0.810 \\
\hline D46 (0) & 1.000 & D46 & 0.635 & 2.206 & - & - & - & - & - & 10.141 & crs & 1.000 \\
\hline D47 & 0.929 & D15, D20, D41, D69 & 2.744 & - & 0.260 & 0.067 & - & 0.831 & - & 11.254 & drs & 0.996 \\
\hline D48 & 0.960 & D15, D69 & 1.573 & - & 0.023 & - & - & - & - & 6.882 & drs & 0.960 \\
\hline D49 & 0.909 & D41, D54, D58 & 0.232 & 0.060 & 0.119 & 0.622 & - & - & - & - & drs & 0.909 \\
\hline D50 & 0.746 & D27, D41, D69 & 0.877 & - & 0.559 & 1.654 & - & - & 0.501 & - & irs & 0.922 \\
\hline D51 & 0.895 & D27, D67, D68, D69 & 0.506 & 0.241 & 0.493 & - & 1.405 & - & - & 0.527 & crs & 1.000 \\
\hline D52 (5) & 1.000 & D52 & - & 0.116 & 0.064 & - & 0.300 & 0.030 & - & - & crs & 1.000 \\
\hline D53 & 0.974 & D52, D54, D61, D69 & 0.496 & 0.118 & - & 0.507 & - & - & 0.078 & 0.491 & drs & 0.974 \\
\hline $\begin{array}{l}\text { D54 } \\
\text { (13) } \\
\end{array}$ & 1.000 & D54 & 0.544 & - & - & 0.276 & 0.230 & - & - & 0.475 & crs & 1.000 \\
\hline D55 & 0.838 & D52, D54, D61, D69 & 0.229 & 0.054 & - & 0.234 & - & - & 0.036 & 0.227 & drs & 0.958 \\
\hline D56 & 0.995 & D59, D67, D69 & 0.949 & 0.372 & - & - & - & 1.501 & 0.488 & - & drs & 0.995 \\
\hline D57 & 0.978 & D61, D69 & 2.450 & - & - & - & - & - & 2.281 & 2.570 & irs & 0.978 \\
\hline D58 (7) & 1.000 & D58 & 1.035 & - & 0.595 & 1.609 & 0.707 & - & - & - & crs & 1.000 \\
\hline D59 (9) & 1.000 & D59 & - & 0.839 & 0.578 & - & 2.394 & 0.003 & - & 0.167 & crs & 1.000 \\
\hline D60 (3) & 1.000 & D60 & 0.460 & 0.345 & 0.045 & 0.434 & - & 0.831 & - & - & crs & 1.000 \\
\hline
\end{tabular}




\begin{tabular}{|c|c|c|c|c|c|c|c|c|c|c|c|c|}
\hline \multirow[t]{2}{*}{ EDO } & \multirow{2}{*}{$\begin{array}{c}\text { TE } \\
(\mathrm{CRS})\end{array}$} & \multirow[t]{2}{*}{ Peers } & \multicolumn{8}{|c|}{ Dual Multiplier Weight } & \multirow{2}{*}{$\begin{array}{c}\text { RTS } \\
\text { Region }\end{array}$} & \multirow{2}{*}{$\begin{array}{c}\text { Scale } \\
\text { Efficienc } \\
y \\
\end{array}$} \\
\hline & & & Y1 & Y2 & Y3 & X1 & $\mathrm{X} 2$ & $\mathbf{X 3}$ & $\mathbf{X 4}$ & $\mathbf{X 5}$ & & \\
\hline D61 (6) & 1.000 & D61 & 0.133 & 0.048 & 0.105 & 0.307 & - & - & 0.101 & - & crs & 1.000 \\
\hline D62 & 0.889 & D60, D61, D69 & 0.838 & 0.084 & - & - & - & 0.716 & 0.625 & - & drs & 0.998 \\
\hline D63 & 0.998 & D17, D27, D67, D69, D77 & 1.172 & 0.610 & 0.297 & - & - & 2.869 & 0.590 & 0.046 & Irs & 0.998 \\
\hline D64 (1) & 1.000 & D64 & 1.987 & 0.788 & - & 2.042 & - & 2.055 & - & - & crs & 1.000 \\
\hline D65 (3) & 1.000 & D65 & 0.389 & 0.116 & - & 0.273 & 0.130 & 0.304 & - & 0.022 & crs & 1.000 \\
\hline D66 & 0.961 & D27, D41, D58, D69 & 0.543 & 0.217 & 0.242 & 1.003 & - & 0.487 & - & - & drs & 0.992 \\
\hline $\begin{array}{l}\text { D67 } \\
(11)\end{array}$ & 1.000 & D67 & - & 1.556 & 0.550 & 2.418 & - & - & - & 1.711 & crs & 1.000 \\
\hline D68 (6) & 1.000 & D68 & 0.422 & - & 0.396 & 0.184 & - & - & 1.144 & - & crs & 1.000 \\
\hline $\begin{array}{l}\text { D69 } \\
(42) \\
\end{array}$ & 1.000 & D69 & 0.808 & 0.168 & 0.180 & - & - & 0.631 & 1.043 & 0.039 & crs & 1.000 \\
\hline D70 & 0.999 & D60, D65, D67, D69 & 1.218 & 0.793 & - & 0.982 & - & 1.714 & - & 0.301 & irs & 0.999 \\
\hline D71 (2) & 1.000 & D71 & 0.041 & 0.045 & 0.024 & 0.170 & - & - & - & 0.004 & crs & 1.000 \\
\hline D72 & 0.787 & D52, D67, D69 & 0.329 & 0.226 & - & - & 0.316 & - & - & 0.855 & $\mathrm{drs}$ & 0.787 \\
\hline D73 & 0.857 & D54, D61, D69 & 0.598 & - & - & 0.520 & - & - & 0.101 & 0.439 & drs & 0.997 \\
\hline D74 & 0.990 & D52, D54, D69 & 0.527 & 0.250 & - & 0.656 & - & - & - & 0.796 & drs & 0.999 \\
\hline D75 & 0.913 & D41, D54, D58 & 0.418 & 0.108 & 0.215 & 1.124 & - & - & - & - & $\mathrm{drs}$ & 0.932 \\
\hline D76 & 0.887 & D27, D69, D77 & 1.337 & 0.441 & 0.078 & - & - & 3.237 & - & - & irs & 0.992 \\
\hline D77 (5) & 1.000 & D77 & - & 0.440 & 0.210 & 0.525 & - & 0.671 & - & - & crs & 1.000 \\
\hline D78 & 0.679 & D69, D77, D80 & 1.274 & 0.414 & - & - & 0.044 & 2.796 & - & - & irs & 0.966 \\
\hline D79 & 0.924 & D41, D54, D61, D69 & 0.715 & - & 0.302 & 1.298 & - & - & 0.167 & 0.017 & drs & 0.988 \\
\hline D80 (3) & 1.000 & $\mathrm{D} 80$ & 1.046 & - & - & 0.434 & - & 1.292 & - & - & crs & 1.000 \\
\hline D81 & 0.727 & D61, D65, D69 & 0.454 & 0.019 & - & - & 0.288 & 0.367 & - & - & $\mathrm{drs}$ & 0.911 \\
\hline D82 & 0.641 & D41, D54, D69 & 1.292 & - & 0.307 & 1.939 & - & - & - & 0.915 & irs & 0.884 \\
\hline
\end{tabular}

NOTE: $E D O=E l e c t r i c i t y$ Distribution Organisation; TE=Technical Efficiency under CRS Technology Assumption; RTS=Return to Scale 
The input-based technical efficiency scores of electricity distributors in table 3 range from 0.606 to 1.000. 28 out of 82 distribution organisations achieve the top (relative) technical efficiency score. The remaining technical inefficiency partially arises from distributors not operating with the most productive scale size. Amongst those, there are 23 distributors operating in irs region while 31 distributors are operating in $d r s$ region. The slack values (indicated -) show extra inefficiencies in related outputs and inputs.

Individual efficiency results suggest that the distribution utilities operating at the relatively more industrialised and developed western part of Turkey have noticeably higher average relative efficiency scores, with performance of distribution utilities deteriorating towards the eastern part of Turkey. The two distribution utilities serving the Anatolian part and the European part of Istanbul respectively, which are not included in the merger programme, have the top efficiency scores. Such findings are consistent with the previous study by Bagdadioglu, Waddams Price, and WeymanJones (1996) and are likely to reflect a less peaky demand, since industrial demand is less seasonally variable than residential load. The Anatolian part of Istanbul used to be served by the private operator Aktas until it was nationalised in 2002. The top score suggests that its efficient performance was not adversely affected in 2003 by nationalisation. In contrast, Kayseri, the only distribution utility privately run throughout the period, presents a poor performance with a relatively low average efficiency score, an interesting finding since its efficiency is measured relative to stateowned utilities where agency problem may be more severe.

In interpreting the details of table 3 our main interest is in those inputs within the control of the distribution organisations where slack is indicated, since organisations are generally faced with a given number of consumers and demand level and service levels are exogenously determined. Similarly the length of the network may also be out of the organisations' control. Amongst the other input variables we note most incidence of slack in the number of transformers. 50 of the 82 organisations have slack in this column, suggesting that they have more transformers than "necessary" for their output levels, relative to best practice. 42 organisations have slack in transformer capacity, suggesting that they could produce the same output with lower capacity. 24 have slack in both transformer related inputs.

Exactly half of the 82 distribution companies have positive slacks for network losses, which includes both technical and non technical losses (theft and unpaid bills). This suggests significant scope for improvement amongst these organisations, but our analysis does not distinguish between 
these two forms of losses. We note that the two companies serving Istanbul, where technical losses would be lower because of the higher population density, do not have slacks in this category, suggesting that it may be dominated by technical losses. However further analysis would be needed to verify this.

39 organisations have slack in the number of employees, suggesting that they could maintain their current output with fewer staff. This is likely to be a particularly sensitive political issue in the reform process. Of course the analysis only defines efficiency and slack relative to others in the sample. For example, if there is overstaffing throughout the industry these results show only where performance is poor relative to the 'least bad' operators.

The scale issue is clearly critical, so we consider how the findings of this paper relate to other results in the literature. Yatchew (2000) investigated economies of scale in electricity distribution by using a semiparametric regression cost function model in which the number of customers was the output scale variable. He finds that minimum efficient scale occurs at about 20,000 customers. Other studies reported by Yatchew indicate a similar result that economies of scale are exhausted at the relatively low level of around 20,000 customers and levels of electricity delivered of 500-3500 GWh. In the sample used in this paper, the technology is modelled directly rather than through cost performance, so that the appropriate concern is with returns to scale in a multiple output framework. In 2003, the average number of customers for the 82 utilities reaches 325,000 and the average annual load delivered is over 1000GWh. Consequently these utilities are of a size for which returns to scale would be exhausted in the findings reported by Yatchew. We used a non-parametric K-S test of the null hypothesis of equality of efficiency distribution functions under constant and variable returns to scale for the pooled sample, as suggested by Banker and Natarajan (2004). The $\mathrm{K}-\mathrm{S}$ p-value for the null is 0.254 so that the null hypothesis of equality of the efficiency distribution functions is not rejected at the 5 or even 10 per cent level of significance. It is clear therefore that returns to scale have been exhausted by the typical utility in the sample, consistent with the findings from the econometric literature. This reinforces the specification of constant returns to scale as the benchmark for the merger efficiency comparisons.

Our results show the possibility of considerable efficiency improvement within the Turkish electricity distribution sector. One way of accomplishing such improvement is by encouraging the inefficient distributors to imitate their efficient peers. An alternative way is to merge distribution organisations to eliminate inefficiency, as proposed by the Turkish Government. 
We now compute the potential efficiency gains for the proposed mergers. The proposal leaves three individual utilities as separate entities, and these act as relative comparators in the sense that their original DEA efficiency scores can be compared with the potential efficiency gains from the proposed merged groups. These separate entities are operating in the Anatolian and European parts of Istanbul, and Kayseri, and their relative efficiency scores in table 3 are 1.000 (D61), 1.000 (D71), and 0.787 (D72), respectively.

In table 4, we set out the efficiency gains from each of the 18 proposed mergers in terms of the crs reference technology, since the mergers involve combining different entitites which will maintain their monopoly service within a particular geographical region. The potential gain from each merger is indicated by the difference between unity and the relevant number in each column. These are shown as potential efficiency gains from the merger $\left(\mathrm{E}^{\mathrm{J}}\right)$, which are primarily driven by the potential "harmony" effect from using better input and output mixes $\left(\mathrm{H}^{\mathrm{J}}\right)$.

Table 4: The Mergers Efficiency Gains from Each Merger under CRS

\begin{tabular}{|c|c|c|c|c|c|}
\hline Merger Areas & $\mathbf{E}^{\mathbf{J}}$ & $\mathbf{E}^{* J}$ & $\mathbf{T}^{\mathbf{J}}$ & $\mathbf{H}^{\mathbf{J}}$ & $\mathbf{S}^{\mathbf{J}}$ \\
\hline MA-1 & 0.711 & 0.716 & 0.993 & 0.716 & 1.000 \\
\hline MA-2 & 0.804 & 0.804 & 1.000 & 0.804 & 1.000 \\
\hline MA-3 & 0.867 & 0.867 & 1.000 & 0.867 & 1.000 \\
\hline MA-4 & 0.836 & 0.836 & 1.000 & 0.836 & 1.000 \\
\hline MA-5 & 0.680 & 0.680 & 1.000 & 0.680 & 1.000 \\
\hline MA-6 & 0.873 & 0.873 & 1.000 & 0.873 & 1.000 \\
\hline MA-7 & 0.741 & 0.741 & 1.000 & 0.741 & 1.000 \\
\hline MA-8 & 0.782 & 0.782 & 1.000 & 0.782 & 1.000 \\
\hline MA-9 & 0.678 & 0.678 & 1.000 & 0.678 & 1.000 \\
\hline MA-10 & 0.811 & 0.811 & 1.000 & 0.811 & 1.000 \\
\hline MA-11 & 0.994 & 0.994 & 1.000 & 0.994 & 1.000 \\
\hline MA-12 & 0.868 & 0.868 & 1.000 & 0.868 & 1.000 \\
\hline MA-13 & 1.000 & 1.000 & 1.000 & 1.000 & 1.000 \\
\hline MA-15 & 0.944 & 0.944 & 1.000 & 0.944 & 1.000 \\
\hline MA-16 & 0.944 & 0.944 & 1.000 & 0.944 & 1.000 \\
\hline MA-19 & 0.857 & 0.857 & 1.000 & 0.857 & 1.000 \\
\hline MA-20 & 0.962 & 0.962 & 1.000 & 0.962 & 1.000 \\
\hline MA-21 & 0.709 & 0.713 & 0.995 & 0.713 & 1.000 \\
\hline \multicolumn{2}{|c|}{ Unwighted average } & 0.837 & & & \\
\hline \multicolumn{2}{|c|}{ Potential saving } & 0.163 & & & \\
\hline \multicolumn{2}{|c|}{ Weighted average } & 0.842 & & & \\
\hline \multicolumn{2}{|c|}{ Potantial saving } & 0.158 & & & \\
\hline
\end{tabular}


As anticipated from both wider literature on electricity distribution, and the non-parametric K-S tests on scale efficiency for this sample, these utilities are typically at a size for which increasing returns to scale have been exhausted. Consequently, it is no surprise that scale or size effects, $\mathrm{S}^{\mathrm{J}}$, play no role in the decomposition of the potential efficiency gains from mergers. Table 4 indicates that $\mathrm{S}^{\mathrm{J}}$ is unity in all cases. (An alternative output-orientation could be a feasible way to incorporate economies of density, Roberts (1986), into the size effect ${ }^{11}$.) However the scores in table 4 indicate that, except for merger area MA-13, there is a considerable potential gain from the proposed mergers in terms of both overall merger efficiency and harmony effects. The scores of individual technical efficiency of the distribution organisations in merged groups are either unity or very close to one, signifying that little potential gain is generated by increased technical inefficiency. However, the potential gain from overall merger and harmony effects is noticeable, ranging between 0.678 and 0.994 . This means that the merger could be advantageous and each merged group could produce the same aggregate outputs using fewer inputs. The harmony measure captures by how much the average input could have been reduced within each merged group in the production of the average output. The mean of $\mathrm{E}^{* J}$ is 0.84 , suggesting that on average $16 \%$ of inputs could be saved if the merger induces best practice. Such potential savings show that the authorities' move to merge the organisations could yield substantial benefits by removing the inefficiencies identified in table 3 .

We have identified the harmony effects as the major source of potential efficiency gains, and it is possible to achieve these without full merger as Bogetoft and Wang (2005) suggest. Since the critical aspect of the harmony gains relates, in this sample, to the elimination of slack in input usage, it is possible that an internal market mechanism, or joint ventures short of full merger, could achieve better use of available input services. Hence the potential efficiency gains identified in this example may be achievable without full scale merger, especially if there is not an issue of shared private ownership of assets.

Finally, we consider whether even more efficiency gains might have been possible if the mergers were allowed to involve distribution organisations independent of their location. Merger of geographically non-contiguous firms is an interesting possibility. The UK electricity distribution network is a major example where geographically non-contiguous firms are operated as separate

\footnotetext{
${ }^{11}$ A referee has suggested this idea to us.
} 
divisions of single regulated firms, and where there is anecdotal evidence of internally co-ordinated responses to network accidents and interruptions. To explore this in the Turkish context, we calculated the efficiency potentials of distribution organisations operating with irs, and present the results in table 5. For these organisations the aforementioned infeasibility problem under the vrs frontier disappears. Most of these mergers show potential gains under vrs as well as crs, and the potential efficiency gains are generally larger than for the proposed mergers. This shows that the geographical constraints of including adjacent organisations in each merger do indeed limit the potential gains available.

Table 5: The Efficiency Gains from Merger of DOs Displacing irs

\begin{tabular}{|c|c|c|c|c|c|c|c|c|c|c|}
\hline \multirow[t]{2}{*}{ NEW MERGER AREAS } & \multicolumn{5}{|c|}{ CRS } & \multicolumn{5}{|c|}{ VRS } \\
\hline & $\mathbf{E}^{J}$ & $\mathbf{E}^{* J}$ & $\mathbf{T}^{\mathbf{J}}$ & $\mathbf{H}^{\mathrm{J}}$ & $\mathbf{S}^{\mathbf{J}}$ & $\mathbf{E}^{\mathbf{J}}$ & $\mathbf{E}^{* J}$ & $\mathbf{T}^{\mathbf{J}}$ & $\mathbf{H}^{\mathrm{J}}$ & $\mathbf{S}^{\mathrm{J}}$ \\
\hline (D18+D19+D21) & 0.850 & 0.850 & 1.000 & 0.850 & 1.000 & 1.022 & 1.022 & 1.000 & 0.875 & 1.168 \\
\hline (D23+D24) & 0.772 & 0.772 & 1.000 & 0.772 & 1.000 & 0.783 & 0.783 & 1.000 & 0.776 & 1.009 \\
\hline (D28+D29) & 0.803 & 0.803 & 1.000 & 0.803 & 1.000 & 1.018 & 1.018 & 1.000 & 0.806 & 1.262 \\
\hline (D32+D35) & 0.897 & 0.897 & 1.000 & 0.897 & 1.000 & 0.915 & 0.915 & 1.000 & 1.000 & 0.915 \\
\hline (D36+D37+D38+D39) & 0.685 & 0.685 & 1.000 & 0.685 & 1.000 & 0.883 & 0.883 & 1.000 & 0.720 & 1.226 \\
\hline (D43+D45) & 0.680 & 0.680 & 1.000 & 0.680 & 1.000 & 0.686 & 0.686 & 1.000 & 0.790 & 0.869 \\
\hline (D78+D82) & 0.586 & 0.586 & 1.000 & 0.586 & 1.000 & 0.587 & 0.587 & 1.000 & 0.636 & 0.924 \\
\hline
\end{tabular}




\section{DISCUSSION, INCENTIVES AND CONCLUDING REMARKS}

Our purpose in the paper is to measure strong efficiency gains empirically, and therefore the ranking of the magnitude of the effect $\left(1-E^{J}\right)$ is the primary concern. However, these effects are sensitive to the assumptions about the technology and further research is needed to relax maintained assumptions such as Convexity.

Our analysis opted to limit the range of scale effects within the merged group, but use of weightrestricted DEA may be an area for further research on the limits on scope or harmony effects as well. Finally, robustness of the results is critical. Our use of pooled data is one simple way to address the issue but an alternative would be to adopt a bootstrapping approach to handle sampling error.

As explained above, the model does not guarantee that the potential gains will be achieved by the indicated mergers. It identifies only a possible gain from the mergers, arising from the measured inefficiency of the aggregated merging distributors. For the potential efficiency enhancement at either individual level or at merged level to be realised, an appropriate incentive mechanism is necessary. Incentives for all of the companies would be expected to change significantly with the reform process. Some change may occur with 'corporatisation' as the entities are prepared for privatisation, and different accountability measures are introduced. However the main effect on incentives is anticipated with change of ownership, when shareholders would want to minimise costs for a given output level (of consumers and quantity of electricity distributed, as well as service quality). If there is an effective mechanism to align managers' incentives with those of shareholders, this should lead to a drive to reduce costs (and therefore inputs) across the industry.

The shareholders' wish to maximise profit would also carry incentives to raise prices, given that each organisation will hold a monopoly in electricity distribution in its relevant area to capture economies of density and avoid wasteful duplication of the network system. The privatised companies will therefore be subject to economic regulation to prevent monopoly exploitation of their consumers, and limit the prices they can charge; the Turkish government has announced that such regulation will be cost based. This raises problems of asymmetric information, since it is difficult for the regulator to identify an efficient level of costs for each privatised company, and to distinguish between costs that are under the companies' control and those that are not. If the 
regulator cannot overcome this asymmetric information challenge, the incentives to reduce costs will be weakened and companies may be able to continue inefficient practices and pass the (inefficient) costs on to consumers through higher prices which are allowed by the regulator. However the DEA analysis described in this paper can also be used as a tool by the regulator to identify whether or not the costs incurred by any one organisation are efficient, through comparison with others in the sector.

In general, the more companies are available for such comparison, the better informed the regulator can become, so the mergers might be seen as weakening a potential regulatory tool. On the other hand, since the mergers result in potentially more efficient companies, the relevance of any one to the regulator in determining the least cost possibilities may be greater. In any case, 21 comparators is a reasonably large number in such circumstances. (The British energy regulator has used comparisons with only 14 distribution companies).

The value of such comparison would be reduced if the cost observations are not truly independent of each other. This might arise if there were collusion between the companies, or if several were owned by the same company. In practice it may be difficult for the Turkish government to find twenty-one fully independent owners for its electricity distribution companies, particularly if it is selling them to foreign owners, where a relatively small number of large companies dominate such international markets. So the government may face a choice between maximising sales proceeds from the flotation and providing the maximum number of independent observations to facilitate the regulator's task after privatisation.

Our analysis examines only the benefits which could be reaped relative to current 'best practice'. Other sources of increased efficiency may arise from the reform process itself. For example it may be possible to acquire inputs more cheaply, or to reduce the general level of staffing in the industry. Private companies will have incentives to explore both these possibilities. If employees are made redundant, it may be appropriate to compensate them in some way, perhaps from the privatisation proceeds which will anticipate the higher profits achievable from such measures.

In conclusion, our analysis has suggested that these mergers can be justified by their potential to provide substantial efficiency gains (an average reduction of inputs of 16\%). These benefits could have been achieved through other methods of spreading best practice, but given the ambition to privatise the companies, merger can provide both the potential for improved efficiency and more 
attractively sized units to offer to the market. The change of ownership is likely to generate efficiency gains through the profit motive, but market power will need to be curbed through regulation which itself can benefit from the comparative analysis methodology presented here. 


\section{REFERENCES}

Akyurek, C. (2006). “The Turkish Crisis of 2001: A Classic?” Emerging Market Finance and Trade 42(1): 5-32.

Al-Sunaidy, A. and R. Green (2006). "Electricity Deregulation in OECD (Organization for Economic Cooperation and Development) Countries.” Energy 31: 769-787.

Arocena, P. (2005). "Economies of Scope and Diversification in the Electricity Industry: a nonparametric frontier analysis." 9th European Workshop on Efficiency and Productivtiy Analysis, $\begin{array}{llll}\text { EWEPA IX, } & \text { Brussels, } & \text { 29-July2, }\end{array}$ http://www.ewepa.org/htmlPages/book.of.abstracts.rev1.pdf

Bagdadioglu, N., C.M. Waddams Price and T.G. Weyman-Jones (1996). "Efficiency and Ownership in Electricity Distribution: A Non-Parametric Model of the Turkish Experience.” Energy Economics 18: 1-23.

Banker, Rajiv D., and R. Natarajan (2004). Statistical Tests Based on DEA Efficiency Scores, in W.W. Cooper, L. Seiford and J. Zhu (eds) Handbook of Data Envelopment Analysis, Boston, Kluwer Academic Publishers.

Bogetoft, P. and D. Wang (2005). "Estimating the Potential Gains from Mergers." Journal of Productivity Analysis 23: 145-171.

Electricity Market Law (2001). Official Journal of Turkey, Law No: 4628. Enactment Date: 03/03/2001. http://www.epdk.org.tr (accessed 16/02/2006)

Electricity Sector Reform and Privatisation Strategy Paper (2004). Privatisation Administration. http://www.oib.gov.tr (accessed 05/02/2006)

EMRA (2004). Annual Report. Energy Market Regulatory Authority http://www.epdk.org.tr (accessed 16/02/2006) 
EMRA (2006). Announcement about Financial Settlement Periods. Energy Market Regulatory Authority. http://www.epdk.org.tr (accessed 16/02/2006)

Erdogdu, E. (2006). "Regulatory Reform in Turkish Energy Industry: An Analysis.” Energy Policy, (in press).

Estache, A., M. A. Rossi and C. A. Ruzzier (2002). "The Case for International Coordination of Electricity Regulation: Evidence from the Measurement of Efficiency in South America." World Bank Policy Research Working Paper 2907. Washington D.C.: World Bank.

European Commission (2003). Directive 2003/54/EC of the European Parliament And Of The Council of 26 June 2003 concerning common rules for the internal market in electricity and repealing Directive 96/92/EC. OJ L176/37.

European Commission (2003). Regulation (EC) No 1228/2003 of the European Parliament and of the Council of 26 June 2003 on conditions for access to the network for cross-border exchanges in electricity. OJ L176/1.

European Commission (2005). Turkey: 2005 Progress Report. 561 Final. European Commission. Brussels, 9 November 2005. SEC(2005), 1426. http://europa.eu.int (accessed 05/02/2006)

Färe, R., S. Grosskopf and C. A. K. Lovell (1994). Production Frontiers. Cambridge: Cambridge University Press.

Hepbasli, A. (2005). "Development and Restructuring of Turkey's Electricity Sector: A Review." Renewable and Sustainable Energy Reviews 9: 311-343.

Jamasb, T. and M. Pollitt (2001). "Benchmarking and Regulation: International Electricity Experience." Utilities Policy 9: 107-130.

Jamasb, T., D. Newbery and M. Pollitt (2004). "Core Indicators for Determinants and Performance of Electricity Sector in Developing Countries." Cambridge Working Papers in Economics CWPE 0438, Cambridge University. 
Jamasb, T., R. Mota, D. Newbery and M. Pollitt (2004). "Electricity Sector Reform in Developing Countries: A Survey of Empirical Evidence on Determinants and Performance." Cambridge Working Papers in Economics CWPE 0439. Cambridge University.

Kwoka, J. E. Jr (2005). "Electric Power Distribution: Economies of Scale, Mergers, and Restructuring." Applied Economics 37: 2373-2386.

Neuberg, L. G. (1977). "Two Issues in the Municipal Ownership of Electric Power Distribution Sytems.” The Bell Journal of Economics 8(1):303-323.

OECD (2003) Annual Report on Competition Policy Developments in Turkey, OECD Competition Committee.

Ozkan F. G. (2005). "Currency and Financial Crises in Turkey 2000-2001: Bad Fundamentals or Bad Luck?" World Economy 28: 541-572.

Ozkivrak, O. (2005). “Electricity Restucturing in Turkey.” Energy Policy 33: 1339-1350.

Roberts, M. J. (1986). "Economies of Density and size in the production and delivery of Electric Power." Land Economics 62: 378-387.

Ruggiero, J. (2004). "Data Envelopment Analysis with Stochastic Data." Journal of the Operational Research Society 55: 1008-1012.

Yatchew, A. (2000). "Scale Economies in Electricity Distribution: a semiparametric analysis." Journal of Applied Econometrics, March/April, 15(2): 197-210. 